\title{
DISASTER RECOVERY SUSTAINABLE HOUSING
}

\author{
Indubhushan Patnaikuni ${ }^{1}$, Robert Oates ${ }^{2}$
}

\begin{abstract}
Disasters due to Natural causes and man-made around the world make many people homeless every year. Disasters such as Pakistan floods in 2010, Haiti earthquake in 2010, Chile earthquake in 2010, Japan earthquake in 2011, Philippines hurricane Yolanda in 2012, the earthquake in Sichuan, China in 2008, the Cyclone Nargis, Mayanmar in 2008 and the 2004 Tsunami remind us of the enormous human suffering and the magnitude of destruction to infrastructure they can cause. In spite of the best efforts of the international disaster response mechanisms currently available, evidence suggests that the most vulnerable among the affected remain entrapped in a vicious cycle of poverty and hopelessness. For these people who are affected the most urgent need is to provide, food, medical assistance, maintaining hygiene and providing shelter within a short timeframe. However, the long-term recovery of affected people would largely depend on their ability to re-gain permanency in housing. This paper focuses on this aspect of response and recovery process and presents a product which is purpose designed not only in providing timely and speedy shelter but also could be used as the formwork in up-grading the temporary shelter to a permanent or semi-permanent home.
\end{abstract} $* * *$

\section{INTRODUCTION}

Chinese officials have announced an international appeal for 3 million tents immediately after the Sichuan earthquake in 2008. It was also reported that in Aceh $42 \%$ of the houses built after the tsunami were not habitable in the long-term. Some of this $42 \%$ were made habitable with further expenditure and retrofit but the rest were demolished or abandoned. This indicates that the housing sector has not shown promising recovery in a long-term perspective in Disaster Response and Recovery (DRR) sphere. The above two aspects highlight two fundamental realities of long-term capability building of such affected communities. There is a huge demand for tents - a quick response temporary shelter as well as a viable semi-permanent housing. Such demand would encourage the researchers and designers to develop innovative solutions, in responding to the housing needs after a disaster, focusing on not only quick response but also the long-term recovery process as a capacity building exercise to the affected people giving hope. It is important to minimise the indirect third party expenditure which otherwise would shrink response delivery budgets. Therefore it makes sense to investigate products and procedures which stimulate recovery. This could only be achieved if such products can demonstrate an alternative building technology that possess three phases of recovery speedy responsiveness, relief and re-development - in a cascading manner inducing hope of recovery within the community. Stigma of being perceived as "temporary" can breed hopelessness and long-term dependency.

The product, H-HUTS presented in this paper encompasses the above mentioned values with several other advantages. UN organisations, FAO, UNOPS, UNESCO, UNDP, UN Secretariat have registered This product. There were offers from other organisations also. Following shows the rationale behind the development of the product in brief:

\section{CONCEPTUAL DEVELOPMENT RATIONALE}

\section{OF H-HUTS}

- H-HUTS shelters are designed and developed to be simple, constructible, affordable, and broadly useful. The concept is based on Japanese origami. This product uses simple materials and hand tools in a unique way to respond to a disaster situation by the way of owner-built housing, with participation by stakeholders across society. Cardboard is main material used for this product which comes from packaging industry. The packaging industry represents about $5 \%$ of global GDP and is well capable of supporting expansion of this project globally (Fig. 1).

- This as an engineered product which is tested for structural adequacy.

- Structures built using this method are very much acceptable and inspire creativity in first-time builders. The product permits windows and door placement without reengineering. It is possible to achieve altered form by removal of modules and choices in conjoining structures, leading to more diverse cultural acceptability (Fig. 2).

- The procedure of building these structures is highly participatory and provides hands-on project activities, as can be seen through the pictures and it can create a feeling of commune and lift corporate social responsibility which could empower the affected community. Industry stakeholders are invited to adapt to their interests, products or services to help meet needs of a given situation at several project stages (Fig. 2) offering opportunities to influence how their products and brand image are viewed in good light of social responsibility. Community engagement and there by capacity building is emphasised.

- It is possible to provide Hands-on school packs to educate, train and build awareness amongst 
younger people.

- $\quad$ As there is no frame and is double-skinned and has well-insulated roof and walls, it allows great economy of materials and energy. Cross ventilation improves comfort levels and also the life span of the cardboard formwork.

- The cardboard as building material, self-financed at about $\$ 0.25$ per person per day and owner labour equity mean the third party expenditure, which otherwise would shrink response delivery budgets, is bypassed.

- Durable and Permanent basic shell structure can be formed using the temporary cardboard skin as formwork using reinforced shotcrete or lightweight concrete after a reasonable recovery period to make the temporary shelter a permanent home. It is quite possible to envisage, with little supervision and assistance, that community taking charge of their own destiny. Reinforcements can be locally available natural fibre such as Coconut, Palm, Bamboo, Banana plant etc. Modern lowmaintenance renders can be used for durability and there is no need of painting.

- From a long-term recovery perspective, affordability linked to capacity in making repayments on borrowings permits greater inclusiveness of the community. Construction costs of converting shelter to a permanent housing are minimal and can be spread over a longer period where affordability to hire someone can be tradeoff against his/her labour capital which enhances the co-operative existence, which is paramount, at the early to middle part of the recovery process.
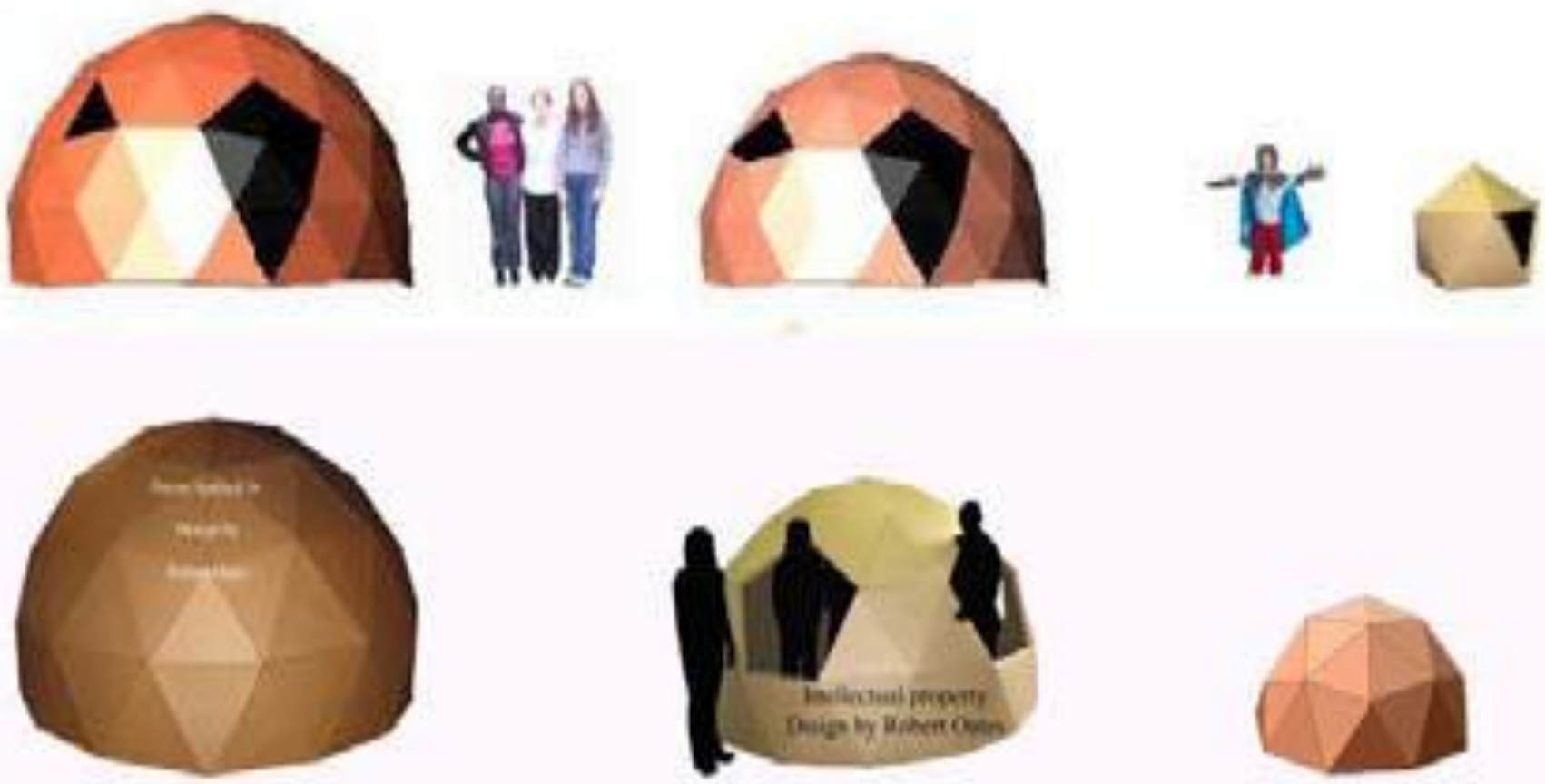

Figure 1: Proposed shelters are constructible, affordable, simple and broadly applicable
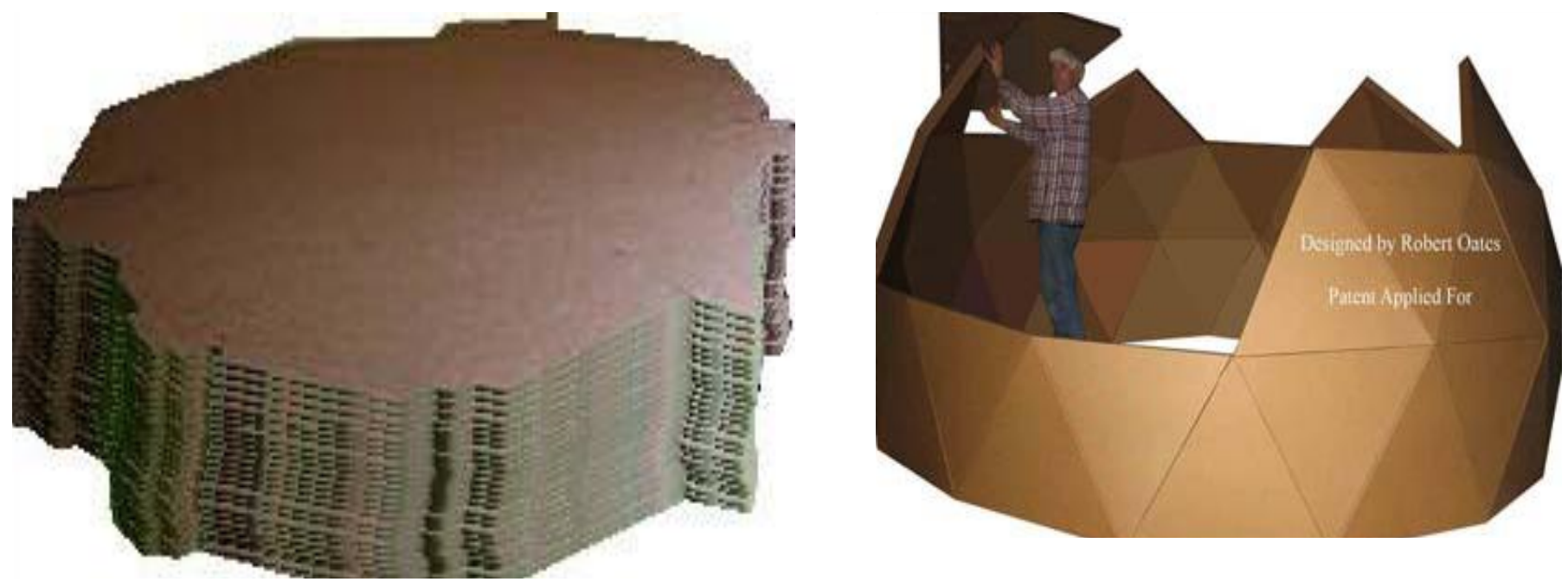

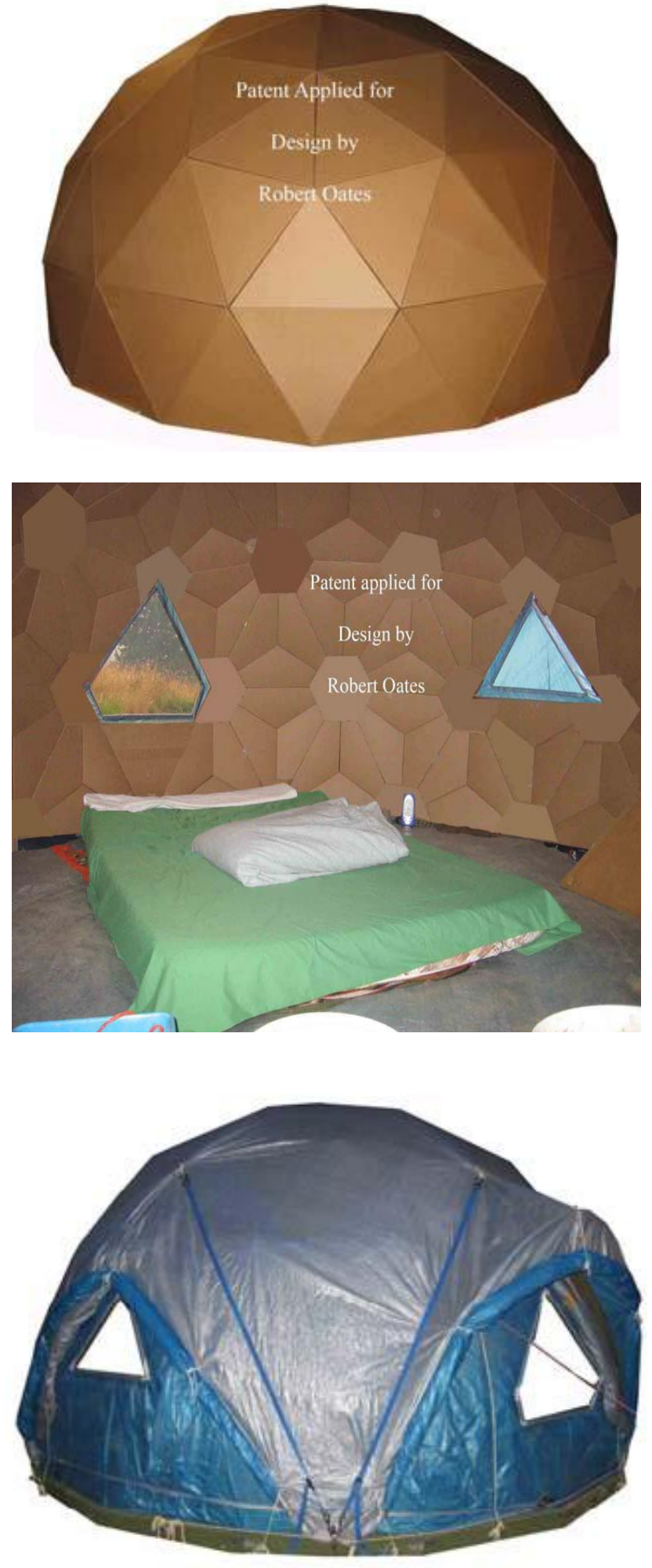

Figure 2: Built structures are perceptually acceptable and inspire creativity in first-time builders.

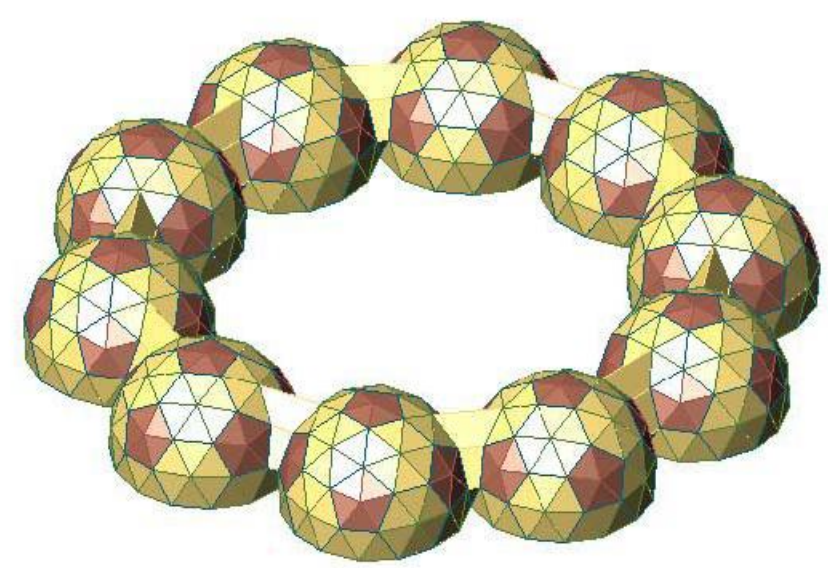

Figure 3: Modules can be combined to form larger enclosures for temporary schooling, communal kitchens and recreation and trauma recovery activities.

\section{SPECIFICATIONS OF CONSTRUCTION SYSTEM AND STRUCTURAL ADEQUACY}

H-HUTS use a modular construction system based on Origami. Origami-made cardboard boxes are fabricated as building modules to make the roof and walls of small, or large, structures. Outdoor structures can be used as emergency shelters by transforming a cover converted from a standard tarpaulin or thick flexible plastic sheets, without requiring sewing or machining. A shelter can be assembled by a person/persons with minimally assisted unskilled labour in a day without requiring power tools.

Properly constructed passageways (Fig. 3) can create larger dwellings or large community space by combining individual modules. They can be made more permanent by upgrading surfaces with a render finishing system, making the cardboard merely redundant formwork. H-HUTS render is lightweight, imparts added structural strength, improves resistance against fire, mould, insect, improves home insulation and improves energy efficiency. Such combined systems are more stable against up-lift due to wind.

H-HUTS renders and exterior plasters are a proposed improved blend of traditional polymeric silicate renders and modern, alkali and weather-resistant, low glass transition polymers to form organo-silicate matrixes. This novel blend vastly improves adhesion, hydration, compressive strength, waterproofing and weathering. It further improves resistance against freezing and thawing in cold conditions. They can be produced in a range of light, stable colours that are very resistant to fading. It does not require painting and the organo-silicate blends have been found to provide outstanding weathering.

H-HUTS renders utilize a new type of interstitial packing to achieve real improvements in insulation properties that are not explained by the types of fillers and silicates employed. Part of the mechanism is thought to be attributed to a change 
in the state of these extenders and aggregates over a relatively narrow temperature range.

Heat probe analysis has shown that $10 \mathrm{~mm}$ of H-HUTS render can supply the insulation of $100 \mathrm{~mm}$ of brick and can be applied much faster at approximately $25 \%$ of the cost of bricklaying. H-HUTS renders will allow a house to be coated in one day. In combination with the low cost rapid response construction method described above, it would transform the temporary shelter to a durable and more permanent structure that would be comparable to a thermal comfort and stability of a standard home.

Table 1: Achievable properties of H-HUTS render (to be verified through testing)

\begin{tabular}{|l|l|}
\hline \multicolumn{2}{|c|}{ H-HUTS renders target properties } \\
\hline Compressive strength & 2000 PSI $(13.88 \mathrm{MPa})$ \\
\hline Weathering & 4000 HOURS $<0.50$ Delta E \\
\hline Water resistance & $<3 \%$ (versus $20-30 \%$ for conventional renders) \\
\hline Permeability & $<3.0($ GRAMS/SQ.M/CM/24 HOURS) \\
\hline Flammability & $0-1(0=$ BEST, $10=$ WORST $)$ \\
\hline Smoke emissions & $0-1(0=$ BEST, $10=$ WORST $)$ \\
\hline Shrinkage & $<0.25 \%(28$ DAYS @ 20 C and 50\% relative humidity) \\
\hline Insulation & 0.33 K FACTOR \\
\hline Adhesion & $250-300$ PSI $(1.74-2.08 \mathrm{MPa}) ;$ Positest pull off cohesion failure only \\
\hline
\end{tabular}

H-HUTS system was also tested by a reputed engineering firm in Australia for static design wind loads. This has involved testing the system under four incremental steps (25\% each) of static loading where $100 \%$ represented cyclone category 1 as per the Australian standards (AS/NZ 1170.2). Results are given in the report GHD $32 / 12624 / 37728$. Shelters have performed well during 11month field trial under normal serviceability conditions as well.

\section{OTHER APPLICATIONS}

H-HUTS also have a great potential in poverty alleviation programs, with or without the community being affected by a disaster. Strategies utilising the cardboard as a building material has extremely low financing needs around 25cents per person per day and owner labour equity allowing financially disadvantaged families to consider improvement in their living standards according to an achievable tiered plan over short to long term time span.

Overarching poverty reduction strategies should integrate and mainstream the whole-of-life disaster preparedness cycle - prevention, response, and recovery/rehabilitation. The idea of incrementally improvable habitat development knowhow, as demonstrated above, and the expertise would undoubtedly enable transitional development capabilities.

\section{CONCLUSION}

1. It is well known that large proportion of the internally displaced people due to disasters stay entrapped in a cycle not being able to recover over a longer period than preferable/envisaged.

2. After any disaster these shelters can be erected in a short time so that the displaced persons do not suffer without shelter.

3. The product can be easily transported in flat packs which do not require large volume of space for transportation.
4. As the product is light weight product transportation costs will be relatively less.

5. The ability not to recover in a short time calls for disaster relief agencies and the concerned agencies to seek more creativeness in seeking sustainable solutions. Post disaster response strategies must be viewed in light of long-term recovery.

6. One major area of concern is housing and it is arguably the most important aspect of the recovery process. Evidence suggests this sector is the weakest and needs more attention and innovation.

7. An affordable and robust solution is presented here which enhances the speed of response and potential for long-term recovery.

8. With further support this product can be improved to cater for the very high demand in future disasters.

9. Product is not only developed and engineered as a technically viable product but also has number of benefits embodied in it to empower the affected community by shifting the stigma associated with hopelessness in people who are affected.

\section{REFERENCE}

[1]. AS/NZ 1170.2 (1989), Wind Loads, Standards Australia, Australia

[2]. GHD - 32/12624/37728, Report for HUT Project, Interim Report on Initial Testing, October 2006 